\title{
$\mathrm{CiSj}$
}

\section{INTEGRATED TOOL SETS FOR BUSINESS GAMES AND SIMULATION}

\author{
Peter J. A. Reusch ${ }^{1)}$, Emine Bozgüney ${ }^{2)}$, Pascal Reusch ${ }^{3)}$ \\ ${ }^{1)}$ University of Applied Sciences Fachhochschule Dortmund Germany, Peter.Reusch@FH-Dortmund.de \\ ${ }^{2)}$ University of Applied Sciences Fachhochschule Dortmund Germany, ebozguney@yahoo.com \\ 3) Bosch Rexroth, Lohr, Germany, reuschp@googlemail.com
}

\begin{abstract}
A lot of methods and tools are used in business games and simulation - mostly isolated so far. Concepts and tools for the integration are presented in this paper with a focus on XML-technologies (XML-/SVG-files, topic maps, ...) and on mind maps and topic maps.
\end{abstract}

Keywords: Business games, business rules, decision tables, simulation, mind maps, topic maps, systems integration.

\section{INTRODUCTION}

Simulation and the application of business games become more and more important. Today typically a set of various business games and simulation tools is used in an organisation for education or training tools to simulate the development and modification of workflows, tools to simulate management decisions in markets, or projects or other issues. The problem today is that the tools remain isolated. We need homogeneous approaches for the preparation of simulation and games, and for the collection and integration of results. A good preparation and a good interpretation of results is an essential part of any simulation. Simulation and business games became strong in the past because they supported a holistic approach of thinking and a good transfer of knowledge. This holistic approach was strong in so far as the simulation model needed a minimal set of objects to run in a way that was more or less "natural". But the holistic approach stopped normally when the model could run - stopped at the limit of one selected simulation system.

Today we are loosing the holistic approach a bit because we have so many approaches we apply separated from each other. This paper is focused on methods and tools for a better integration of business games and simulation in an overall modelling and controlling concept.

Simulation is a very fundamental approach in training and education, in research and development, and in learning organisations. Simulation has a long tradition. Since decades tools are available to support simulation like GPSS [15] - strong in the 1960's and 1970's - or SIMUL8 ${ }^{\circledR}$ [6] - now more popular for discrete simulation than GPSS.
Simulation can also be based upon business rules and tools like Common Knowledge Studio [29].

For an overall simulation of business administration since over 20 years there are management simulations like those provided by TOPSIM $^{\circledR}$ [25] - today used in hundreds of universities and companies. The management simulation based on TOPSIM GM - General Management - is a model representing a company. The participants of the simulation take over the management role of a company. They compete in groups against other simulated companies in a simulated market. Through their decisions, the participants influence the success of "their" company. So they learn about the interdependencies in and around a company and about the internal and external factors that affect its economic success they test and develop concepts and rules.

After the successful introduction of business games for general management simulation 10-20 years ago, now new games are available for special kinds of companies or special management functions. Today in the TOPSIM ${ }^{\circledR}$ package there is a management simulation for example for banking, ecommerce, project management - TOPSIM PM - or change Management - TOPSIM CM [25].

\section{INTEGRATION OF BUSINESS GAMES}

Fig. 1 shows a typical set of tools for simulation and business games - with selected TOPSIM ${ }^{\circledR}$ tools and some classical tools like GPSS or SIMUL8 ${ }^{\circledR}$.

Whatever we simulate we should start with an analysis of the context - an analysis of objects and roles, concepts and structures, rules and effects. There are methods and tools to prepare the 
simulation. An object role analysis can help to identify the objects we have to represent in a simulation model. There are strong tools supporting object role analysis and object role models [2] - and they can really make good contributions - but these tools are better known among experts in computer science than in business administration - the home area of business games. If there is not enough expertise in advanced object role modelling, it would be better to start some structural analysis and object role analysis based upon mind maps. Mind maps are used in education and higher education almost everywhere. Tools like Mind Manager [3] or Think Graph [21] support mind mapping. The files of the mind maps stored by Mind Manager or Think Graph are XML-files. So the information in these files can be linked with other tools or can be extracted for further applications.

The object role analysis or structural analysis should be carried forward to an influence analysis or cause effect analysis. When we play business games, we have to make decisions. And we can only make good decisions, if we know the most important factors in the game - those factors with strong influence on others. In the group of the TOPSIM games GAMMA can support influence analysis and cause effect analysis. Otherwise Visio or other universal tools can be used. Cause effect diagrams and influence diagrams developed with Visio can be stored in XML files.

After the application of structural analysis we look for other issues of our simulation model. We analyse workflows before we start with GPSS or SIMUL8 ${ }^{\circledR}$, we analyse enterprises and markets before we start with TOPSIM GM, we analyse the scope, the tasks and the resources of a project before we start TOPSIM PM, and we analyse the organisation - including roles and interactions of people in the organisation that we want to develop before we start TOPSIM CM to support change management. And when we finish the simulation we have to analyse the results.

Table 1 shows some methods and tools that can contribute to the integration of business games and simulation and are often used in the context of business games today. Mind Maps are used for structural analysis - Mind Manager ${ }^{\circledR}$ [3], Think $\mathrm{Graph}^{\circledR}$ [21] and Visio ${ }^{\circledR}$ [27] are tools to support Mind Mapping ${ }^{\circledR}$. Object role analysis [2] can be supported using the ORM module of Visio ${ }^{\circledR}[1]$ for example. Decision tables are useful to describe rules - PROLOGA [6] is a tool appropriate to develop and check rules, apply rules and generate code for further applications - a tool that can contribute to the development of a knowledge base with business rules [12], [13].

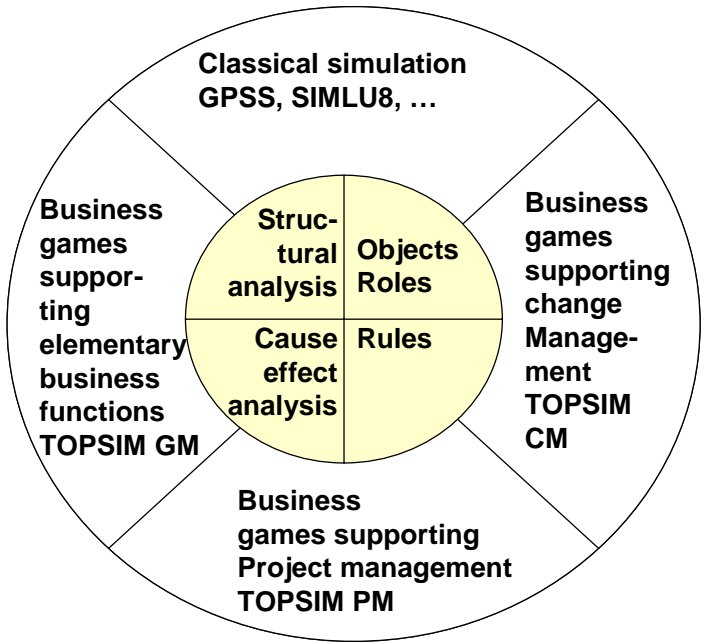

Fig 1. - Business Games and Simulation - and Supporting Methods and Tools.

Table 1: Selected Methods and Tools Supporting Business Games and Simulation

\begin{tabular}{|c|c|c|c|}
\hline Approach & Method & Tools & $\begin{array}{l}\text { Aspects re- } \\
\text { garding the } \\
\text { integration }\end{array}$ \\
\hline \multirow[t]{2}{*}{$\begin{array}{l}\text { Object Role } \\
\text { Analysis }\end{array}$} & $\begin{array}{l}\text { Classical } \\
\text { Object-Role- } \\
\text { Modelling } \\
\text { (ORM) [2], [8] }\end{array}$ & $\begin{array}{l}\text { Visio - ORM } \\
\text { Tools of Terry } \\
\text { Halpin [2] }\end{array}$ & $\begin{array}{l}\text { XML-SVG } \\
\text { export }\end{array}$ \\
\hline & $\begin{array}{l}\text { Topic Maps [5], } \\
\text { [22], [23], [24] }\end{array}$ & \begin{tabular}{|l|} 
Omnigator [4] \\
and various \\
other tools \\
\end{tabular} & $\begin{array}{l}\text { Topic maps are } \\
\text { XML based }\end{array}$ \\
\hline \multirow{4}{*}{$\begin{array}{l}\text { Structural } \\
\text { Analysis }\end{array}$} & & $\begin{array}{l}\text { Mind } \\
\text { Manager }^{\circledR}[3]\end{array}$ & $\begin{array}{l}\text { XML + XML- } \\
\text { schema }\end{array}$ \\
\hline & Mind Mapping & $\begin{array}{l}\text { Thinkgraph } \\
{[16]}\end{array}$ & $\begin{array}{l}\text { XML-SVG + } \\
\text { Topic Map }\end{array}$ \\
\hline & & $\begin{array}{l}\text { Visio }^{(B)} \text { - mind } \\
\text { mapping subset } \\
{[28]}\end{array}$ & $\begin{array}{l}\text { XML-SVG } \\
\text { export }\end{array}$ \\
\hline & $\begin{array}{l}\text { System Analysis } \\
\text { and others }\end{array}$ & $\begin{array}{l}\text { Visio - various } \\
\text { subsets [28] }\end{array}$ & $\begin{array}{l}\text { XML-SVG } \\
\text { export }\end{array}$ \\
\hline \multirow{2}{*}{$\begin{array}{l}\text { Cause } \\
\text { Effects } \\
\text { Analysis }\end{array}$} & $\begin{array}{l}\text { Ishikawa } \\
\text { Diagrams [16] }\end{array}$ & Visio [27] & $\begin{array}{l}\text { XML-SVG } \\
\text { export }\end{array}$ \\
\hline & $\begin{array}{l}\text { Influence } \\
\text { Graphs [25] }\end{array}$ & GAMMA [25] & $\begin{array}{l}\text { Belongs to } \\
\text { TOPSIM tool } \\
\text { set [10] - is } \\
\text { nevertheless } \\
\text { isolated }\end{array}$ \\
\hline \multirow{3}{*}{ Rules } & $\begin{array}{l}\text { Decision Table } \\
\text { [12], [13] }\end{array}$ & PROLOGA [6] & $\begin{array}{l}\text { XML + XML } \\
\text { schema }\end{array}$ \\
\hline & $\begin{array}{l}\text { Decision Table } \\
\text { [12], [13], } \\
\text { Decision Grid, }\end{array}$ & $\begin{array}{l}\text { Common } \\
\text { Knowledge } \\
\text { Studio [29] } \\
\end{array}$ & XML \\
\hline & $\begin{array}{l}\text { Decision Table } \\
\text { [12], [13], } \\
\text { Decision Grid, }\end{array}$ & $\begin{array}{l}\text { ILOG JRules } \\
{[30]}\end{array}$ & $\begin{array}{l}\text { XML + XML } \\
\text { schema }\end{array}$ \\
\hline \multirow{3}{*}{ Workflows } & UML [26] & [26] & {$[26]$} \\
\hline & $\begin{array}{l}\text { Workflows and } \\
\text { other methods } \\
\text { combined }\end{array}$ & \begin{tabular}{|l|} 
Common \\
Knowledge \\
Studio [29] \\
\end{tabular} & XML \\
\hline & & \begin{tabular}{|l|} 
ILOG JRules \\
{$[30]$}
\end{tabular} & $\begin{array}{l}\text { XML + XML } \\
\text { schema }\end{array}$ \\
\hline
\end{tabular}


There are other tools like Common Knowledge Studio [29] or ILOG JRules [30] with a core focus of business rules. Such tools can also be taken as a starting point to develop games and simulation and to support the integration of methods as mentioned in chapter $\mathrm{V}$.

\section{MIND MAPS AND TOPIC MAPS SUPPORTING INTEGRATION}

For the preparation of business games and simulations we can use mind maps. Mind maps can also help to document the whole process starting with the preparation of business games, going thru the simulation, and including the interpretation of the results of the simulation.

The following figure shows such a mind map with components regarding the documentation (status, version, author of the mind map; objectives, requests, objects of the simulation). The description of the object types of the planned simulation follows. Finally there are contributions regarding methods and tools applied - and results collected. This map is not fully expanded in the figure - many branches are folded.

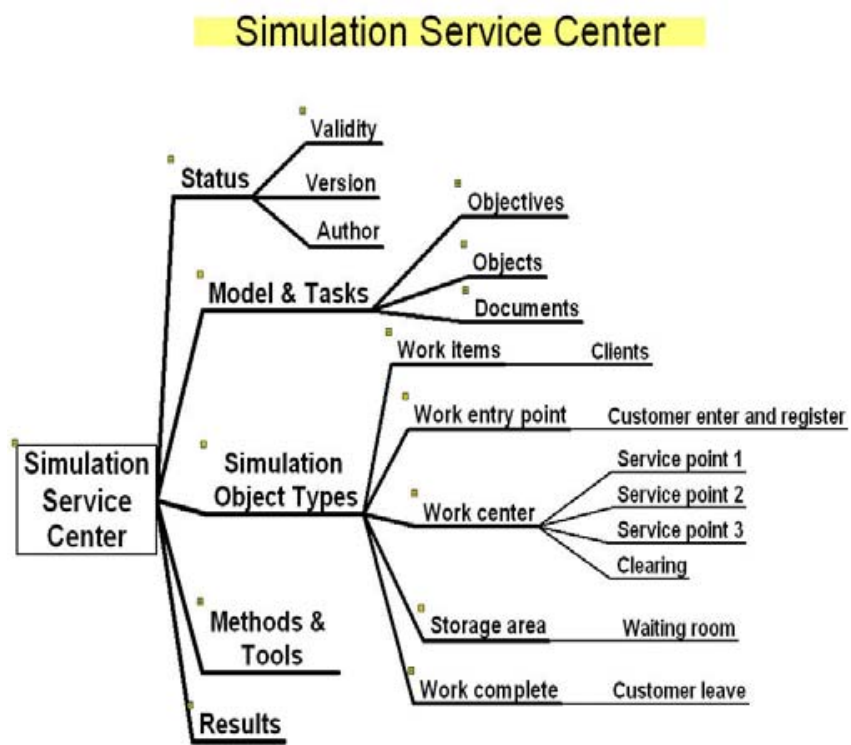

Fig. 2. - Mind Map Describing Components of the Model for the Simulation of a Service Center.

This mind map was developed with Think Graph. The map is stored in an XML-file. This file includes a topic map representation of the map - part of which is shown in the figure below [5],[22],[23],[24].

This topic map can be exploited by a topic map browser like OMNIGATOR [4] in the same way it is shown in [13] and [14]. So the expanded topic map can contribute to a web portal for the whole simulation model with all components of the mind map above.

Such topic maps can also be embedded in elearning systems supporting the training of simulation [7].

The graphical representation of the mind map above is available in XML-SVG-elements [20], [21].

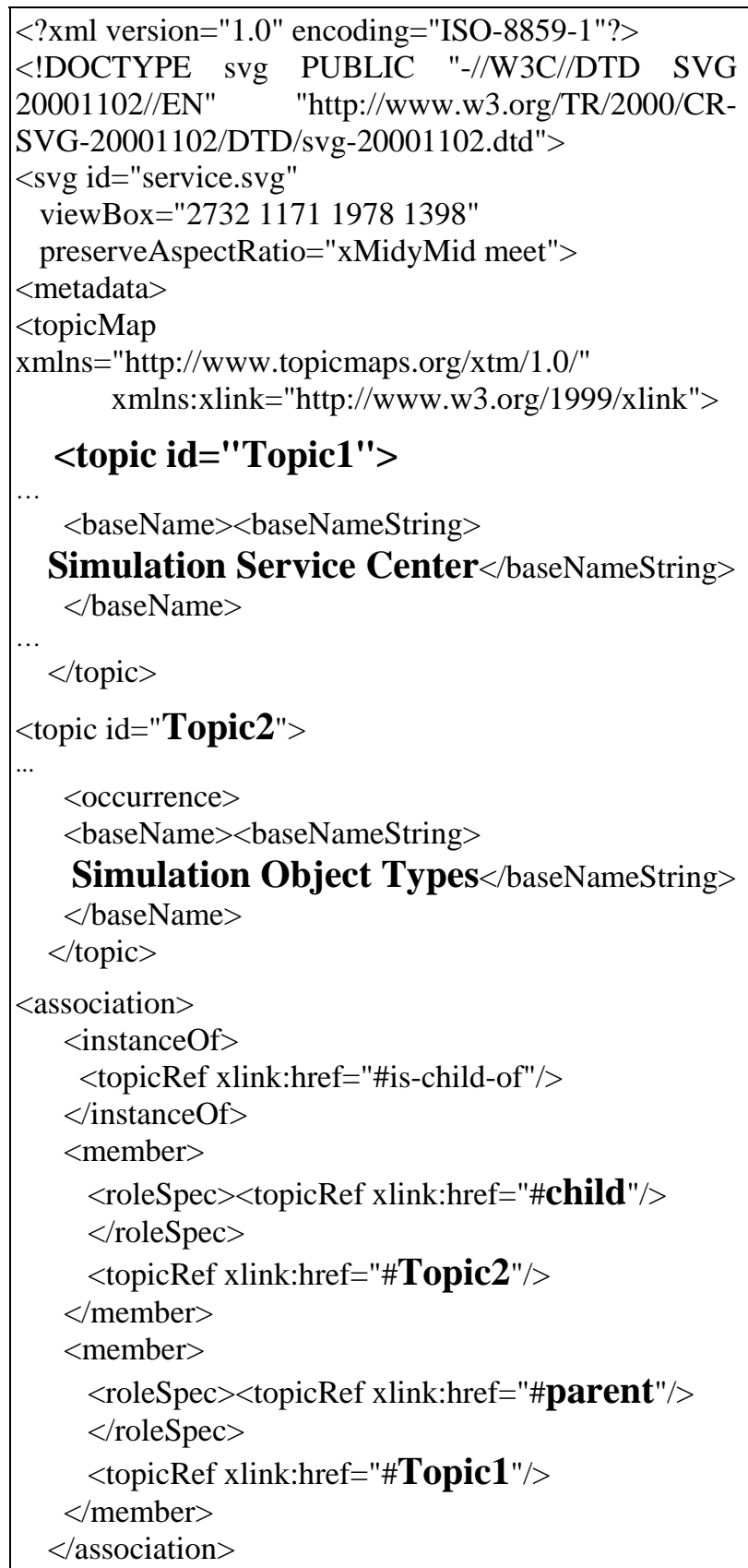

Fig. 3. - Some Topics from the Think Graph Representation of the Mind Map in Fig. 2.

The results of the preparation are used for the implementation of the simulation model in a tool like SIMUL8. The simulation objects are transferred directly. The description of special methods and tools can be added - for example the description of statistical distributions used in the model.

The mind map is the core module that collects all 
information about the preparation, the execution and the evaluation of the simulation. The corresponding topic map includes all the topics, associations and occurrences of the mind map and can be exploited by a topic map browser.

\section{XML MODELS IN SIMULATION TOOLS}

The following figure shows the graphical representation of the simulation model prepared in the mind map above. The simulation objects were transferred to SIMUL8. The figure shows 7 simulation objects - one work entry point (Customer enter and register - above), one storage area (Waiting room), 4 work centers (clearing, service points 1-3) and one work complete unit.

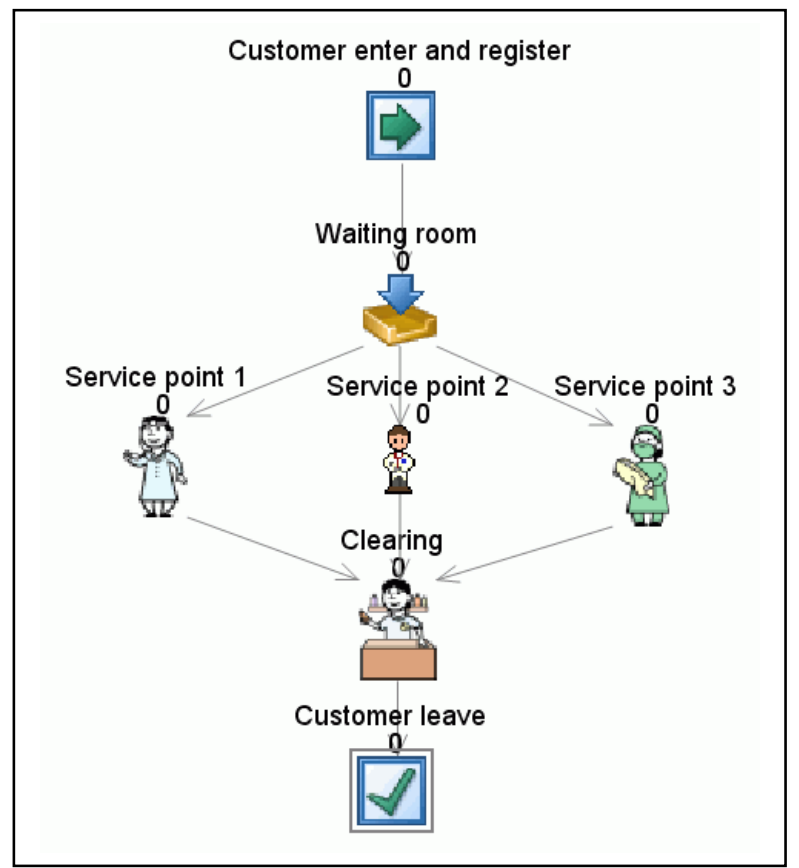

Fig 4. - Graphical Representation of the Simulation Model for the Service Center in SIMUL8.

During the simulation customers arrive at the work entry point above, move thru service stations, and leave the model at the customer leave unit below.

The next figure shows the XML-representation of the simulation objects used by SIMUL8. This kind of representation highly supports system integration in simulation models.

Regarding system integration in simulation it is very easy to link or even transfer specifications of the core components form the mind map to the simulation tool. But in the XML-specification of the mind map there are a lot of objects dealing with locations and layout. And in the XML-file of the corresponding SIMUL8-application there are much more objects than in the figure below - also dealing with locations and layout, but also with parameters and results of the simulation.
The graphical elements in the specification of the simulation model are XML-based - but not according to the SVG-standard. Regarding system integration this is unimportant since the locations and layout of elements in the mind map will not have corresponding locations and layout in SIMUL8.

After the application of the simulation model the results will be described - using SIMUL8 result tables and other sources - and the results will be collected in documents linked to the mind map.

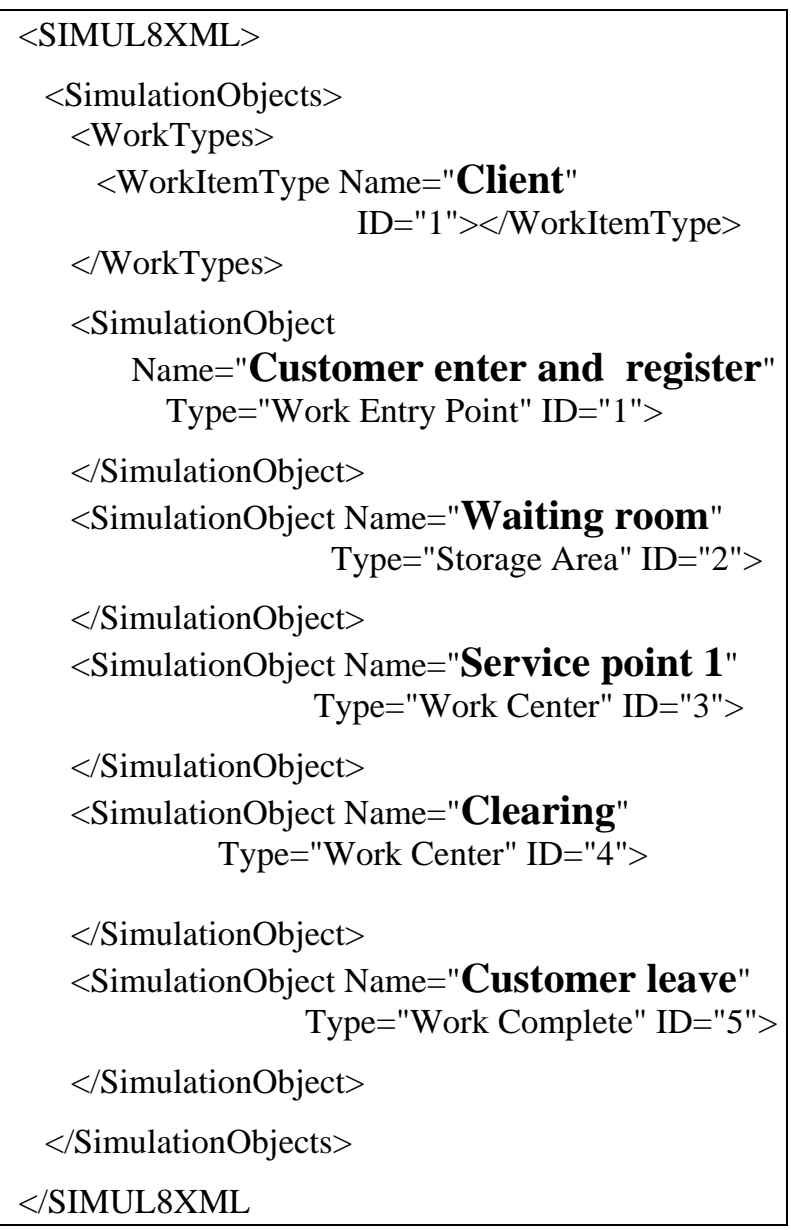

Fig 5. - The XML-Specification of the Simulation Model for the Service Center in SIMUL8 Identification of the Simulation Objects.

\section{New Systems from the Field of Business Rules and Decision Tables}

Any simulation is based upon a model with entities, workflows, and rules. And there are new tools now available to support the development and the application of business rules that can contribute to simulation - and to the integration of methods and tools.

One such tool is Common Knowledge Studio [29]. The following figure shows part of the representation of the service center mentioned above in Common Knowledge Studio. Here we can 
describe the context of the service center application. The core definitions are part of a knowledge base that includes classes, channels, objects, etc.. The entities of the service center are defined as objects.

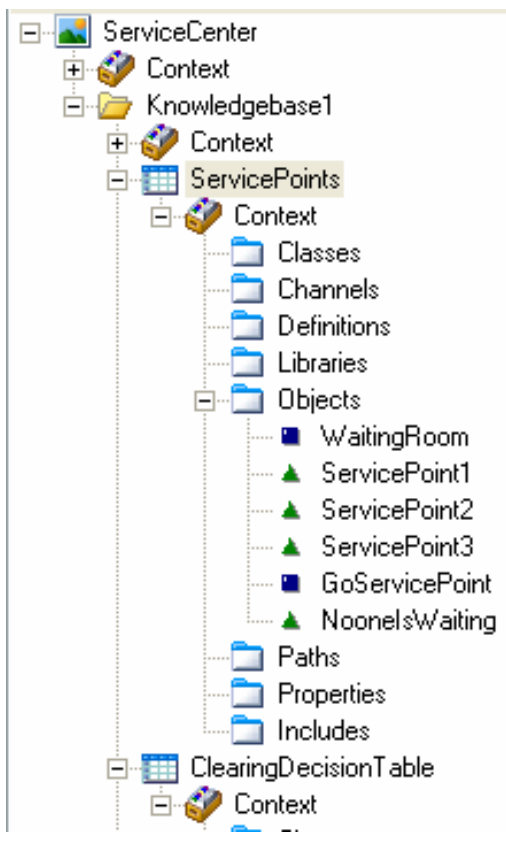

Fig 6. - Entities of the service center model defined in Common Knowledge Studio.

The knowledge base for the service center further includes decision tables to describe the flow of customers through the service center - one is shown below.

\begin{tabular}{|c|c|c|c|c|c|}
\hline & Rule1 & Rule2 & Rule3 & Rule4 & Rule5 \\
\hline WaitingRoom & $>0$ & $>0$ & $>0$ & $>0$ & 0 \\
\hline ServicePoint1 & true & false & false & false & \\
\hline ServicePoint2 & & true & false & false & \\
\hline ServicePoint3 & & & true & false & \\
\hline GoServicePoint & 1 & 2 & 3 & & \\
\hline Wait1 & false & false & false & true & true \\
\hline NoOnelsWaiting & & & & & true \\
\hline
\end{tabular}

Fig 7. - One of the decision tables for the service center model defined in Common Knowledge Studio.

Based upon these definitions one can start the application. A consultation of the decision tables for the service center is possible in Common Knowledge Studio when the specification of the model is appropriate. The following figure shows the protocol of a case with a customer available in the waiting room who is transferred to service point 2.

\begin{tabular}{|c|c|c|c|c|c|}
\hline & Rule1 & Rule2 & Rule3 & Rule4 & Rule5 \\
\hline WaitingRoom & $>0$ & $>0$ & $>0$ & $>0$ & 0 \\
\hline ServicePoint1 & true & false & false & false & \\
\hline ServicePoint2 & & true & false & false & \\
\hline ServicePoint3 & & & true & false & \\
\hline GoServicePoint & 1 & 2 & 3 & & \\
\hline Wait1 & false & false & false & true & true \\
\hline NoOnelsWaiting & & & & & true \\
\hline
\end{tabular}

Fig 8. - Protocol of the application of a decision table.

Such consultations can be combined to run a full simulation.

Another important point for a simulation model based upon Common Knowledge Studio is the fact that within the knowledge base of the application besides entities and decision tables or decision grids also workflows can be specified as shown in the figure below.

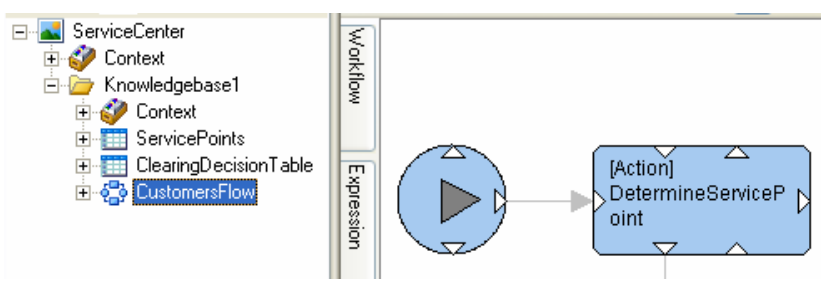

Fig 9. - Part of the workflow of the service center.

A consultation of the service center model can also be started by using the workflow - or in this case the description of the flow of customers - as shown in the figure below.

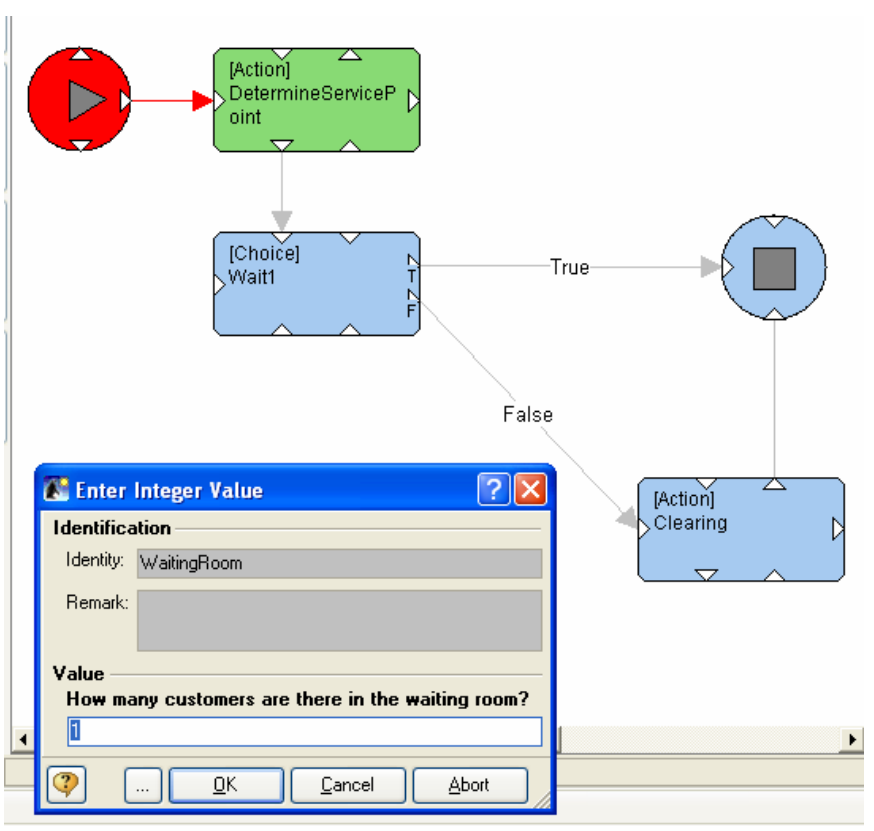

Fig 10. - Consultation based upon the work flow. 
The concept of Common Knowledge Study will be helpful in the future to support semantical models for applications specified by describing classes, entities, rules, and workflows.

For the context of this paper Common Knowledge Studio can also be used to support system integration for simulation based upon XML-files. The following figure shows part of the specification of a work center by Common Knowledge stored within a XML-file.

$<$ TOCContextClass ...Identity="WorkCenter">

$<$ TOCUserClass ...Identity="WorkCenter" Caption="WorkCenter">

$<$ TOCObjectBase ... TakesOwnership="true">

$<$ TOCUserClassPropertyAttribute Identity="busy" Caption="busy" ...>

$<$ TOCUserClassPropertyAttribute

...Identity="idal" Caption="idal" ...>

$</$ TOCObjectBase $>$

$</$ TOCUserClass $>$

$<$ TOCContextClass $>$

Fig 11. - Some XML-elements for the specification of the service center in Common Knowledge Studio.

\section{INTEGRATION MODELS FOR THE MANAGEMENT OF BUSINESS SIMULATION}

The approaches applied so far to integrate methods and tools in business games and simulation can be unified in an integration model as shown in the figure below with 5 phases.

Orientation: Business games and simulation start with an orientation. We have to collect information, discuss with others, we have to analyze and develop structures. All that can be supported for example by mind maps and mind mapping tools.

Specification: Then we have to specify the simulation model. We have to describe simulation objects and methods and tools to use in detail.

Implementation: Then the specification has to be implemented using a simulation tool like SIMUL8.

Application: Then the simulation tool is used to run the simulation, to check results, to test various parameters and constellations.

Controlling: Finally the results of the simulation are compared with the information collected in former phases. And documents will be added to the mind map we started with - arrow 4 in the figure below.

\section{Management of Business Simulation}

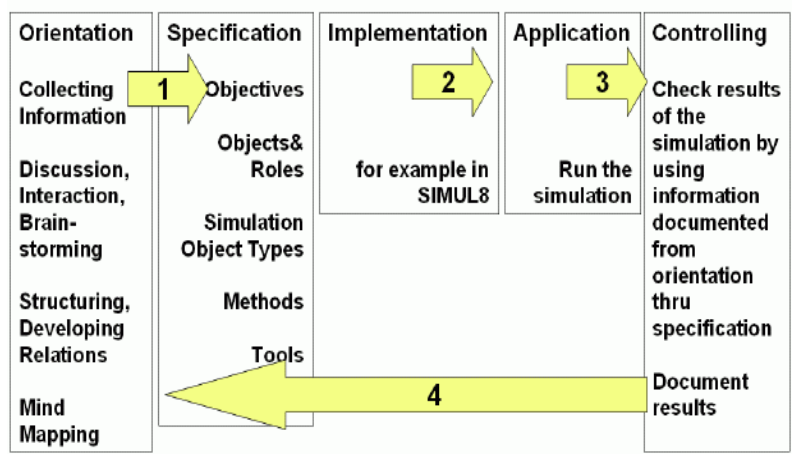

Fig. 12. - Integration Model for the Management of Business Simulation.

This is a general approach - nevertheless it is useful to remember want we have to consider when we want to develop and apply simulation models. This approach helps as to focus on the links and bridges - and not only on the isolated parts of the simulation model.

\section{REFERENCES}

[1] European Master in Project Management. EuroMPM. www.eurompm.net.

[2] Terry Halpin. Database Modeling. New York 2003 - refers to the ORM module of Visio ${ }^{\circledR}$.

[3] Mind Manager. http://www.mindjet.com/.

[4] Omnigator. http://www.ontopia.net/omnigator/ models/index.jsp.

[5] Ontopia. www.ontopia.net/topicmaps/ materials/tao.html.

[6] PROLOGA. http://www.econ.kuleuven.be/ prologa/.

[7] Pascal Reusch. Topic Maps Supporting eLearning Systems. Thesis University Cologne, 2003.

[8] Peter J. A. Reusch, Jean-Jacques Wintraeken. Systemanalyse und Systemspezifikation. Mannheim, 1990.

[9] Peter J. A. Reusch. Simulation Methods and Educational Games for Project Management. The $10^{\text {th }}$ International Workshop of the IFIP WG 5.7 Special Interest Group on Experimental Interactive Learning in Industrial Management, Trondheim, 2006.

[10] Peter J. A. Reusch. Entwicklung der Kommunikation und Kooperation in Projekten auf der Grundlage von XML. PMFORUM'2006, IPMA-GPM 2006.

[11] Peter J. A. Reusch, Pascal Reusch, Bastian Stoll. Communication in Projects - New Techniques and Improved Concepts, $1^{\text {st }}$ ICEC \& IPMA Global Congress on Project 
Management and $5^{\text {th }}$ World Congress on Cost Engineering, Project Management \& Quantity Surveying, Ljubljana, Slovenia, 2006.

[12] Peter J. A. Reusch, Julia Gdaniec, Emine Bozguney, Pascal Reusch. New Perspectives for Decision Tables in Project Management, IPMA World Congress, Cracow 2007.

[13] Peter J. A. Reusch, Julia Gdaniec, Emine Bozguney, Pascal Reusch. New Perspectives for The Management of Business Rules based upon Decision Tables, IEEE IDAACS Workshop, Dortmund, 2007.

[14] Peter J. A. Reusch, Emine Bozguney. Topic Map Tools to Support Business Simulation, EuroMPM Research Report, Dortmund, 2007.

[15] Thomas J. Schriber. An Introduction to Simulation Using GPSS/H. Wiley, 1991.

[16] Six Sigma - Ishikawa Diagram. http://www. isixsigma.com/tt/cause_and_effect/.

[17] SIMUL8: http://www.simul8.com/.

[18] S. Spreeuwenberg. Business Rules in Models. Requirements for Standardization, http://www.omg. org/docs/ad/03-01-14.pdf.

[19] SPSS Software. http://www.wolverinesoftware. $\mathrm{com} /$.

[20] SVG Scalable Vector Graphics: http://www.w3.org/TR/SVG/.

[21] Think Graph. http://www.thinkgraph.com/

[22] Topic Maps. http://www.topicmaps.org.

[23] Topic Maps. - ISO 13250. - http://www. topicmaps.org/xtm/1.0/

[24] Topic Maps. http://www.topicmap.com.

[25] TOPSIM. http://www.topsim.com/en/Games/.

[26] UML. http://www.uml.org/.

[27] Jan Vanthienen. Ruling the Business: About Business Rules and Decision Tables http://www.econ.kuleuven.be/tew/academic/inf osys/members/VTHIENEN/download/Papers/b r_dt.pdf.

[28] Visio. http://visio.mvps.org/.

[29] Common Knowledge Studio. http://www. objectconnections.com/.

[30] ILOG JRules. http://www.ilog.com/.

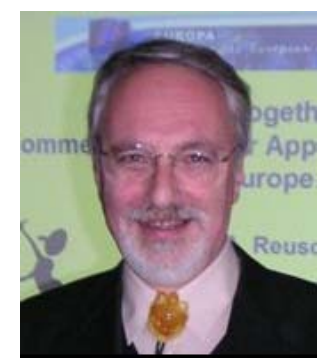

Prof. Peter Reusch was born in Germany in 1950. In 1976 he received the $P h D$ degree in Computer Science from the University of Bonn. He is honorary doctor of the State Economic University in Minsk and of the University of Latvia in Riga. At present he works as Professor at the University of Applied Sciences in Dortmund and is course director of the European Masters in Project Management - EuroMPM. He is chair of the international consortium running the EuroMPM in Bilbao, Trondheim, Paris/Lille, and Dortmund. He is vice-president universities of $P M I^{\mathrm{TM}}$ chapter Cologne. He is co-chair of the Scientific Advisory Board of the e-Commerce Group at the Cologne Institute for Business Research. He is a member of the IDAACS Group. He teaches and makes contributions on research and development in several institutes in various countries.

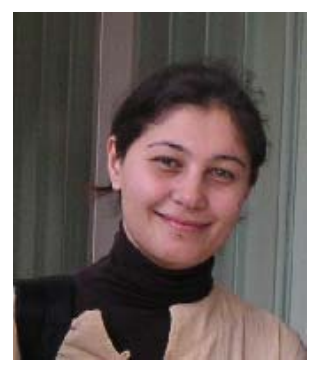

Emine Bozgüney was born in Turkey in 1981, studied industrial engineering at the Middle East Technical University, worked as quality insurance engineer in an automotive company, and then came to Germany to join the European Master in Project Management in Dortmund.

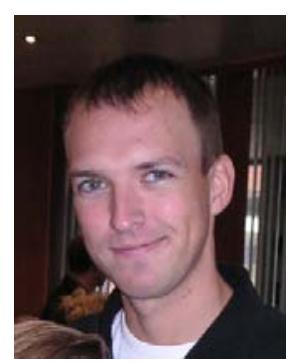

Dr. Pascal Reusch was born in Germany in 1980. He studied business informatics at the University of Cologne. In 2006 he received the $P h D$ degree in Business Administration from the University Duisburg-Essen. After some years working as consultant he is now working at 